This item was submitted to Loughborough's Research Repository by the author.

Items in Figshare are protected by copyright, with all rights reserved, unless otherwise indicated.

\title{
Elite swimmers possess shorter telomeres than recreationally active controls
}

PLEASE CITE THE PUBLISHED VERSION

https://doi.org/10.1016/j.gene.2020.145242

PUBLISHER

Elsevier BV

VERSION

AM (Accepted Manuscript)

PUBLISHER STATEMENT

This paper was accepted for publication in the journal Gene and the definitive published version is available at https://doi.org/10.1016/j.gene.2020.145242.

\section{LICENCE}

CC BY-NC-ND 4.0

\section{REPOSITORY RECORD}

Nickels, Matt, Sarabjit Mastana, Matthew Denniff, Veryan Codd, and Liz Akam. 2020. "Elite Swimmers Possess Shorter Telomeres Than Recreationally Active Controls". Loughborough University. https://hdl.handle.net/2134/13234472.v1. 
1 Elite swimmers possess shorter telomeres than recreationally active controls

2 Nickels M, Mastana S, Denniff M, Codd V, Akam E 


\section{ABSTRACT}

4 Purpose: Elite athletes are reported to possess longer telomeres than their less active counterparts. ACE gene (Insertion/Deletion) polymorphism has been previously associated with elite athletic performance, with the deletion (D) variant appearing more frequently in short distance swimmers. Additionally, the D allele has been reported to have a negative effect on telomere length. The aim of this study was to investigate the telomere length of elite swimmers and its potential association with ACE genotype. Methods: Telomere length was measured by real-time quantitative PCR and ACE I/D genotypes analysed by standard PCR and electrophoresis in 51 young elite swimmers and 56 controls. Results: Elite swimmers displayed shorter telomeres than controls $(1.043 \pm 0.127$ vs $1.128 \pm 0.177, \mathrm{p}=0.006)$. When split by sex, only elite female swimmers showed significantly shorter telomeres than their recreationally active counterparts $(\mathrm{p}=0.019)$. ACE genotype distribution and allelic frequency did not differ between elite swimmers and controls, or by event distance among elite swimmers only. No association was observed between telomere length and ACE genotype in the whole cohort. Conclusions: Elite swimmers possessed shorter telomeres than recreationally active controls. Our findings suggest a negative effect of high-level swimming competition and/or training on telomere length and subsequent biological aging, particularly in females. However, this significant difference in telomere length does not appear to be attributed to the D allele as we report a lack of association between telomere length and ACE genotype frequency in elite swimmers and controls.

Keywords: Athlete, Aging, Exercise and Genetics 
Telomeres are repeat nucleotide sequences $\left(5^{\prime}-\mathrm{TTAGGG}_{\mathrm{n}}-3^{\prime}\right)$ located at chromosome ends that confer genomic stability. Telomeres progressively shorten with each round of cell division and are considered to be a biomarker of biological aging (Huda et al., 2007). Shorter telomeres are associated with several age-related diseases (e.g. cardiovascular disease, cancer, diabetes) and an increased risk of mortality (Rizvi et al., 2015). Lifestyle factors including nutrition, sleep, stress management and physical activity (PA) have all been proposed to influence telomere length (TL) (Starkweather, 2014). For example, middle-aged and older individuals with higher levels of PA typically display longer telomeres than their sedentary counterparts (Cherkas et al., 2008; Saßenroth et al., 2015), although the effect of PA on TL in young individuals is less clear. The majority of the literature reports no association of PA with TL in young individuals (LaRocca et al., 2010; Østhus et al., 2012), although recent studies have provided evidence that PA-mediated effects on telomere maintenance may begin in adolescence/young adults (Mofrad and Ebrahim, 2018; Zhu et al., 2011). The lack of association between PA and TL in young individuals may partly be explained by an absence of significant age-related telomere attrition and/or insufficient exposure to PA levels (e.g. activity years). Nevertheless, a cohort of young elite athletes $(27.2 \pm 4.9 \mathrm{y})$ have been reported to possess longer telomeres than sedentary agematched controls (Muniesa et al., 2017), suggesting that extremely high levels of exercise training, such as those performed by elite athletes, may be required in order to influence TL in young individuals.

Angiotensin converting enzyme (ACE) converts the hormone angiotensin I to the active vasoconstrictor angiotensin II. Angiotensin II has numerous actions, including promotion of a pro-inflammatory environment and increased oxidative stress (Fyhrquist and Saijonmaa, 2008), both of which are proposed to shorten TL (Correia-Melo et al., 2014). A 287-base AluI polymorphism in intron 16 has been described (Insertion (I) / Deletion (D)) within the ACE 
gene, resulting in three possible genotypes (II, ID and DD) (Rigat et al., 1990). The presence of the D allele has been linked with increased circulating ACE activity levels compared with II homozygotes (Rigat et al., 1990), which may lead to enhanced inflammation and oxidative stress. Interestingly, hypertensive patients with left ventricular hypertrophy with ID or DD genotypes display shortened leukocyte telomeres, suggesting a potential negative effect of the D allele on TL (Fyhrquist et al., 2013). It is well documented that the ACE D allele is associated with elite short distance swimming, and the ACE I allele with elite middle- and long-distance events (Costa et al., 2009; Nazarov et al., 2001; Tsianos et al., 2004; Woods et al., 2001). However, no study has investigated the notion that elite short distance swimmers may possess shortened telomeres compared with their middle- and long-distance counterparts due to the potential negative effect of the ACE gene D allele.

The primary aim of the present study is to investigate TL and ACE genotype in elite swimmers and recreationally active controls.

\section{MATERIALS AND METHODS}

\subsection{Ethics Approval}

Approval was obtained from the ethics committee of Loughborough University (R18-P175). The procedures used in this study adhere to the tenets of the Declaration of Helsinki. Informed consent was obtained from all individual participants included in the study.

\subsection{Participants}

A complete health assessment was completed for each participant using a structured questionnaire. Exclusion criteria for the study were known metabolic disorders, smoking, 
cardiovascular disease, use of anti-inflammatory medication or steroids, any condition or disease that may interfere with the primary outcome measurement.

The study population comprised 51 elite young swimmers (characteristics in Table 1.), reporting an average training distance of $43,196 \pm 9,408 \mathrm{~m} /$ week, reaction time of $0.69 \pm 0.07 \mathrm{~s}$ and FINA point score of $805 \pm 82$. All swimmers were currently competing at a minimum of national level, ranging up to Olympic standard (66\% National, 2\% European Championships, 8\% Commonwealth Games, 14\% World Championships, 10\% Olympics). Swimmers were further categorised into three distinct categories based on their main event distance $(41 \%$ sprint $(\leq 100 \mathrm{~m}), 39 \%$ middle $(\leq 200-800 \mathrm{~m})$, and $20 \%$ long $(\geq 800 \mathrm{~m}))$.

A cohort of 56 healthy, age-matched control subjects were recruited. Control subjects were recreationally active and participated in a minimum 150 minutes of moderate PA, or 75 minutes of vigorous PA, per week. However, they were not involved in any structured training programme or competitive sports.

\subsection{Anthropometric measurements}

Height was measured using a Seca 213 stadiometer (Seca GmbH, Germany). Weight, body fat percentage (BF\%), fat free mass (FFM) and body mass index (BMI) were quantified using the Tanita BC-418 MA segmental body composition analyser (Tanita Corporation, USA). 
Table 1. Characteristics of elite swimmers and controls

\begin{tabular}{lcccc}
\hline & Female controls & Female swimmers & Male controls & Male swimmers \\
& $n=29$ & $n=22$ & $n=27$ & $n=29$ \\
\hline \hline Age (years) & $19.6 \pm 2.2^{*}$ & $20.5 \pm 1.4$ & $20.3 \pm 4.7$ & $20.6 \pm 1.7$ \\
Height $(\mathrm{cm})$ & $165.1 \pm 6.3^{*}$ & $171.4 \pm 5.9$ & $178.4 \pm 6.0^{*}$ & $183.5 \pm 5.3$ \\
Weight $(\mathrm{kg})$ & $61.7 \pm 10.8$ & $65.5 \pm 6.3$ & $72.4 \pm 12.2^{*}$ & $77.7 \pm 6.8$ \\
BMI (kg/m $)$ & $22.7 \pm 3.4$ & $22.3 \pm 1.8$ & $22.7 \pm 3.5$ & $23.0 \pm 1.4$ \\
Body fat $(\%)$ & $27.5 \pm 6.0^{*}$ & $20.4 \pm 3.9$ & $14.0 \pm 4.1^{*}$ & $11.1 \pm 2.8$ \\
FFM (kg) & $44.4 \pm 4.5^{*}$ & $52.1 \pm 5.0$ & $62.0 \pm 8.8^{*}$ & $69.0 \pm 5.6$ \\
\hline
\end{tabular}

Data are means $\pm \mathrm{SD}$; $n$, no. of subjects. BMI, body mass index. FFM, fat free mass.

*Significant group effect.

\subsection{Sample collection and DNA extraction}

Participants collected buccal samples themselves using Isohelix DNA buccal swabs (Cell

Projects Ltd, UK) following visual and verbal instructions. Samples were immediately placed in the microcentrifuge tube provided and kept at room temperature for a maximum of 2 hours, before being stored at $-80^{\circ} \mathrm{C}$ until DNA extraction. DNA was extracted from buccal cells using the ReliaPrep ${ }^{\mathrm{TM}}$ gDNA Tissue Miniprep System (Promega, USA) according to the manufacturer's instructions. The quantity and quality of genomic DNA was assessed by spectrophotometry using a NanoDrop 2000 (ThermoFisher, USA), producing acceptable 
Measurement of buccal cell TL was conducted at the University of Leicester using the qPCR protocol previously described (Nickels et al., 2020). Telomere primer sequences were Tellb GGCTTGCCTTACCCTTACCCTTACCCTTACCCTTACCCT-3', both diluted to a final concentration of 300nM. Primer sequences for the single-copy gene (36B4) were 36B4F 5'-

CCCATTCTATCATCAACGGGTACAA -3', both diluted to a final concentration of 500nM.

Final reaction volume was $25 \mu \mathrm{L}$, consisting of $22 \mu \mathrm{L}$ of qPCR master mix (SensiMix $^{\mathrm{TM}}$ SYBR $®$ No-ROX Kit, Bioline) and primers (targeting either the telomere or single copy gene) and $3 \mu \mathrm{L}$ of gDNA template $(10 \mathrm{ng} / \mu \mathrm{L})$. Telomere $(\mathrm{T})$ PCR cycling conditions consisted 0 $95^{\circ} \mathrm{C}$ for $10 \mathrm{~min}, 20$ cycles of $95^{\circ} \mathrm{C}$ for $15 \mathrm{sec}$ and $58^{\circ} \mathrm{C}$ for $1 \mathrm{~min}$. Single-copy gene (S) PCR cycling conditions consisted of $95^{\circ} \mathrm{C}$ for $10 \mathrm{~min}, 30$ cycles of $95^{\circ} \mathrm{C}$ for $15 \mathrm{sec}$ and $58^{\circ} \mathrm{C}$ for $1 \mathrm{~min}$. Telomere and single copy gene runs were performed separately, starting with former and followed immediately by the latter to keep conditions uniform. To ensure intra-run reliability each sample was run in duplicate. Any duplicate samples which had take-off values exceeding 0.2 of a cycle difference were excluded and re-run. To ensure inter-run reliability all PCR reactions were performed twice on two separate days using a Rotorgene Q (Qiagen, Germany). Alongside the samples, each run also contained a calibrator sample (pooled DNA) and no template control in duplicate. The average intra-plate coefficient of variation for calculated $\mathrm{T} / \mathrm{S}$ ratio was 3.3\%. The average inter-plate coefficient of variation for calculated $\mathrm{T} / \mathrm{S}$ ratio was 4.1\%. Relative $\mathrm{T} / \mathrm{S}$ ratios were calculated using the Qiagen Rotorgene comparative quantitation software (Qiagen, Germany). 


\subsection{ACE genotyping}

138

ACE genotype was determined using the following primers; forward, 5' CTGGAGACCACTCCCATCCTTTCT 3'; and

reverse, $5^{\prime}$

GATGTGGCCATCACATTCGTCAGAT 3', which were designed to amplify the polymorphic region from human genomic DNA. The PCR of 35 cycles, each with denaturation at $95^{\circ} \mathrm{C}$ for 30 seconds, annealing at $60^{\circ} \mathrm{C}$ for 90 seconds, extension at $72^{\circ} \mathrm{C}$ for 30 seconds, followed by a final cycle of 10 minutes at $66^{\circ} \mathrm{C}$ was conducted. PCR products were electrophoresed on $2 \%$ $w / v$ agarose gel detected as 190-bp fragments in the absence of the insertion (D allele) and a 490-bp fragments in the presence of the insertion (I allele). 15\% of samples were randomly repeated to check the validity of the genotyping. No errors were observed.

\subsection{Statistical analysis}

The normality and homogeneity of data were verified by the Shapiro-Wilk and Levene tests, respectively. The independent $t$-test or analysis of variance (ANOVA) was used to examine differences in mean TL, anthropometrics, genotype and performance data between groups. An analysis of covariance (ANCOVA) was also used to compare differences between groups when necessary. All associations were tested by two-tailed Pearson correlation. Allele frequencies were estimated by gene-counting method. Genotype distribution and allele frequencies between groups were compared by Chi-Square test, as were estimates of Hardy-Weinberg equilibrium. All analyses were performed using SPSS 23.0 (IBM Corporation, USA) with pvalues $<0.05$ considered significant. 


\section{RESULTS}

\subsection{Telomere length}

163

164

165

166

167

168

169

170

171

172

173

174

175

176

177

178

179

Data analysis revealed control subjects possessed longer telomeres $(1.128 \pm 0.177)$ than elite swimmers $(1.043 \pm 0.127)(\mathrm{p}=0.006$, calculated effect size $=0.55)$ (Figure 1$)$. This group effect remained significant after adjusting for all covariates $(p=0.031)$. When analysed by sex, female swimmers displayed significantly shorter telomeres $(1.049 \pm 0.115)$ than female controls $(1.154 \pm 0.176)(p=0.019$, calculated effect size $=0.70)$, which remained significant after adjusting for all covariates $(\mathrm{p}=0.012)$. There was no difference in TL between male swimmers $(1.039 \pm 0.136)$ and male controls $(1.099 \pm 0.176)(\mathrm{p}>0.05)$. There was no significant sex difference in TL for all participants after adjusting for covariates (males: 1.068 \pm 0.158 , females: $1.109 \pm 0.160, p=0.114)$. 2

\subsection{Lack of association between telomere length and swimming performance}

TL was not associated with swimming performance (FINA points) $(\mathrm{n}=50, \mathrm{p}=0.420, r=$ $0.117)$, reaction time $(\mathrm{n}=33, \mathrm{p}=0.398, r=0.152)$, average weekly training distance $(\mathrm{n}=51$, $\mathrm{p}=0.613, r=-0.073)$, main event distance $(\mathrm{p}=0.661, r=0.063)$ or highest level of competition $(\mathrm{p}=0.487, r=0.099)$ in swimmers overall. The lack of associations remained when swimmers were analysed by separate groups based on their $\operatorname{sex}(p>0.05)$. 


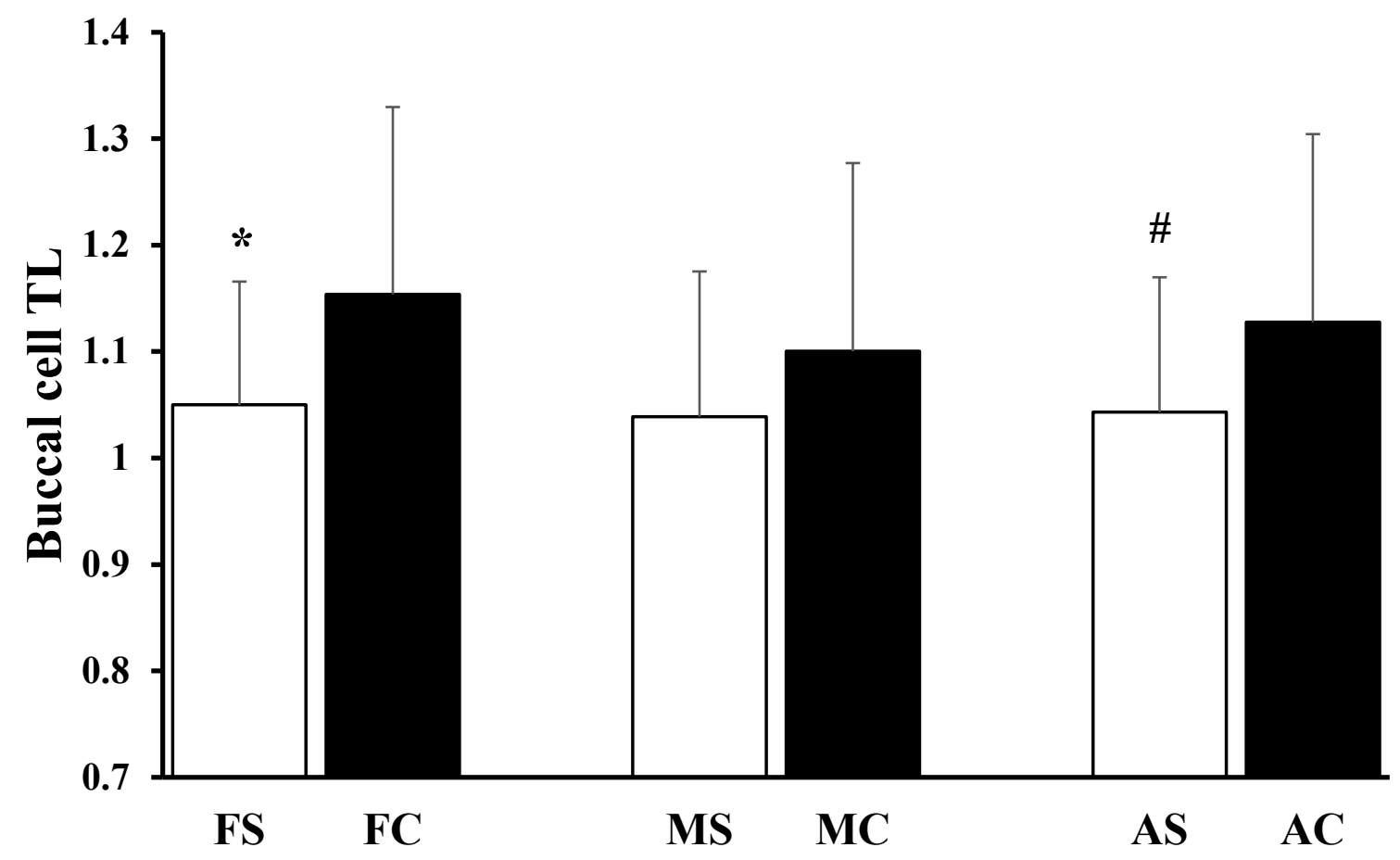

181 Fig. 1 Buccal cell TL for female swimmers (FS), female controls (FC), male swimmers (MS), male controls (MC), all swimmers (AS) and all controls $(\mathrm{AC})($ mean $\pm \mathrm{SD})$. *: different from FC; \#: different from AC. Statistical significance defined as p-values $<0.05$.

\subsection{ACE I/D genotype and allele frequency}

Genotypic frequencies in both swimmers and controls was consistent with Hardy-Weinberg equilibrium. There were no statistical differences for genotype and allele distributions between swimmers and controls overall (Table 2) or when analysed by distinct groups based on sex (p $189>0.05)$. Furthermore, no statistical differences were observed for genotype distributions and allelic frequencies when the swimmers were stratified into three groups based on main event $>0.05)$ (Figure 2). 
Table 2. ACE genotype distribution and allele frequencies of swimmers and controls

\begin{tabular}{lcccccc}
\hline Subjects & $n$ & \multicolumn{3}{c}{ ACE genotype } & \multicolumn{3}{c}{ Allele frequency } \\
\cline { 3 - 7 } & & DD & ID & II & D & I \\
& & & & & & 0.51 \\
Swimmers overall & 50 & $13(0.26)$ & $25(0.50)$ & $12(0.24)$ & 0.49 \\
Sprint & 21 & $6(0.29)$ & $11(0.52)$ & $4(0.19)$ & 0.55 & 0.45 \\
Middle & 19 & $7(0.37)$ & $7(0.37)$ & $5(0.26)$ & 0.55 & 0.45 \\
Long & 10 & $3(0.3)$ & $7(0.7)$ & $0(0.0)$ & 0.65 & 0.35 \\
Controls & 54 & $12(0.22)$ & $29(0.54)$ & $13(0.24)$ & 0.49 & 0.51 \\
& & & & & & \\
\hline
\end{tabular}

195

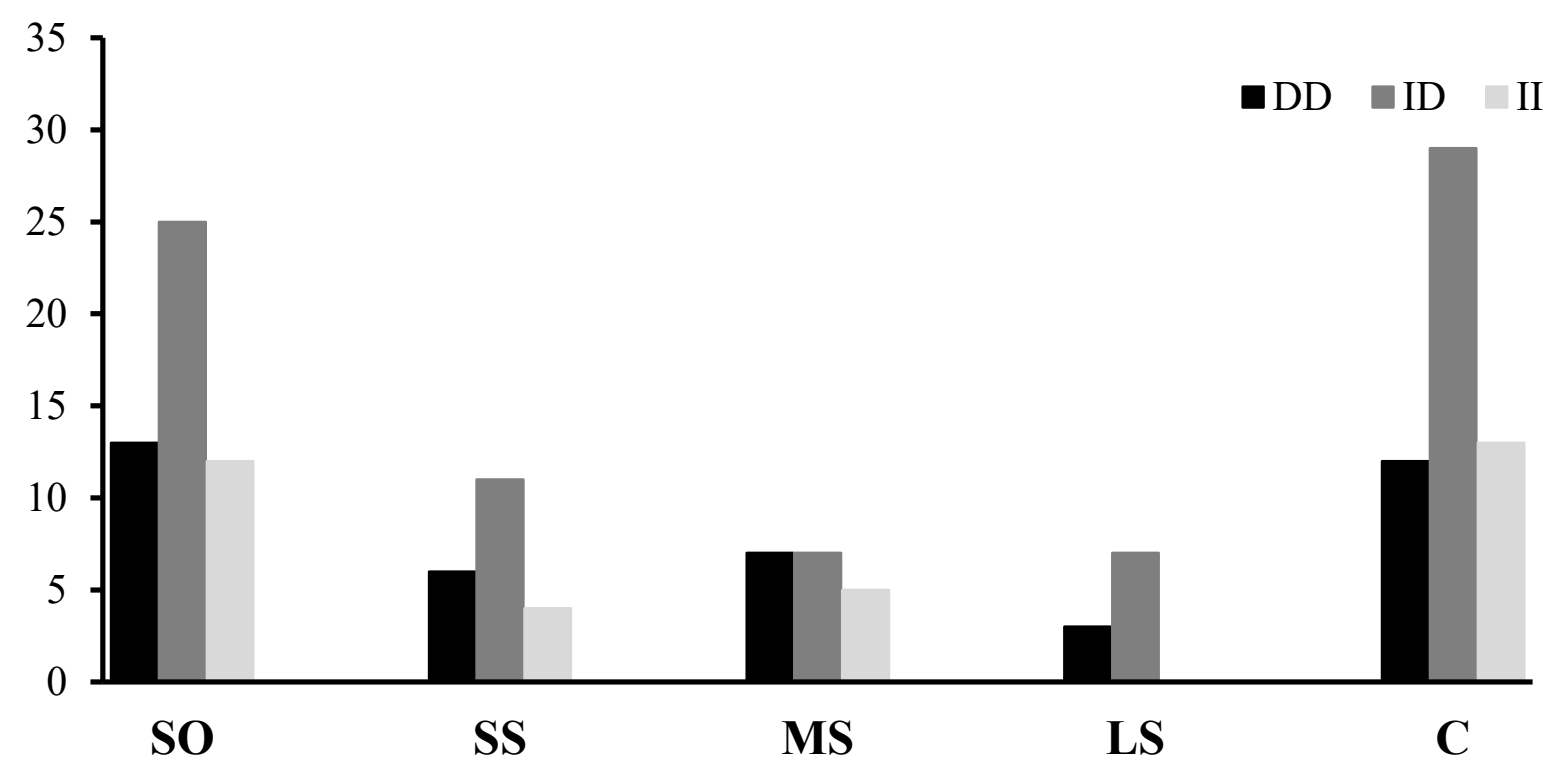

197

Group

198 Fig. 2 ACE I/D genotype frequencies amongst swimmers overall (SO), sprint swimmers

199 (SS), middle-distance swimmers (MS), long-distance swimmers (LS) and controls (C). 


\subsection{Telomere length and ACE I/D genotype}

202

203

204

205

206

207

208

209

210

211

212

213

214

215

216

217

218

219

220

221

222

223

In the whole cohort, TL was not associated with ACE I/D genotype ( $p>0.05)$. Furthermore, TL was not associated with ACE I/D genotype when the cohort was stratified into distinct groups of swimmers, controls or split by sex $(\mathrm{p}>0.05)$. There was also no association between TL and ACE I/D genotype when swimming groups were individually analysed by main event distance $(p>0.05)$.

\section{DISCUSSION}

The main findings of the present study are that: 1) elite swimmers display shorter TL compared with their recreationally active peers, which appears specific to females; 2) buccal cell TL is not associated with ACE I/D genotype; 3) swimming main event distance is not associated with ACE I/D genotype distribution.

There is a progressive loss of telomeres with each round of cell division and they eventually reach a critically short length, culminating in replicative senescence (Olovnikov, 1973). However, engagement in moderate levels of PA is associated with longer telomeres and may preserve their length (Cherkas et al., 2008; Saßenroth et al., 2015). Conversely, middle-aged and older individuals with extremely low or high PA levels appear to exhibit shorter telomeres than their moderately active counterparts (Cherkas et al., 2006; Savela et al., 2012). To highlight, individuals with extremely high levels of PA have been reported to display telomeres comparable in length to their low PA level counterparts (Ludlow et al., 2008). As such, an 'inverted U' relationship between PA level and TL has been proposed, in which low and extremely high levels of PA may be detrimental to TL and lead to accelerated shortening (Ludlow et al., 2008). 
In the present study, the relative TL of young recreationally active control subjects was $8.1 \%$ greater than the elite swimmers. When that data was analysed split by sex, female controls displayed telomeres $9.9 \%$ longer than elite female swimmers. The lack of difference in TL observed between male controls and swimmers indicates that participation in elite level swimming training/competition may be detrimental to telomere maintenance and subsequent biological aging in females. We cannot be certain that these findings are biologically relevant at such as young age, but short buccal cell telomeres have been associated with age-related disease (Broberg et al., 2005; Thomas et al., 2008). These major findings are in contrast with previous data that reported young high-level international athletes possess longer leukocyte TL (LTL) than healthy controls (Muniesa et al., 2017). The discrepancy in these findings may be explained by the fact that the elite athletes used in the study by Muniesa et al. were recruited from a wide variety of sport specialties (running events $>1500 \mathrm{~m}$, triathlons, weightlifting, judo, gymnastics, canoeing, basketball, soccer, taekwondo), each of which generates different metabolic demands (Muniesa et al., 2017). Several other studies investigating TL and PA in young individuals have involved non-elite athletes and have reported no difference in TL between active and sedentary individuals (LaRocca et al., 2010; Østhus et al., 2012; Werner et al., 2009). This may be because young individuals have not accumulated enough training years/volume, or they are yet to experience any significant age-related telomere attrition. Nonetheless, we are the first to demonstrate that extremely high training loads can be with the results reported by Muniesa et al., it appears that the physical demands of elite level sports competition/training may provide a novel stimulus that is able to both positively, and 
Rae et al. have previously reported that skeletal muscle TL was inversely correlated with the number of hours and years spent training in older endurance runners (Rae et al., 2010). Additionally, it has previously been reported that individuals with high PA (exercising 10-14 hours/week) possess shortened TL compared with moderately active individuals (Ludlow et al., 2008). At the time of data collection, swimmers were in competition season and training $\sim 14$ hours/week in the pool alone (excluding any additional training). Thus, despite a lack of association between the average weekly training distance and buccal cell TL amongst swimmers in the present study, the high number of training hours they performed may potentially explain their shortened telomeres compared with the recreationally active controls. Furthermore, highly trained middle-aged endurance athletes experiencing 'exerciseassociated chronic fatigue' or 'overtraining' report significantly shorter skeletal muscle TL compared with age- and training-matched athletes free from these symptoms (Collins et al., 2003). Although we did not specifically diagnose whether the swimmers were 'overtrained' in the present study, we can only speculate that some of them may have been in such a associated with overtraining (Margonis et al., 2007) and shortened TL (Correia-Melo et al., 2014) may explain the results of the present study. It is important to reiterate that whilst this is biologically plausible, we cannot deduce such a conclusion from our findings and that

267 further research is required.

Due to time constraints and the nature of the study cohort, we were only permitted to collect DNA from the swimmers using non-invasive procedures. TL is typically measured in leukocytes extracted from venous blood, which would have permitted us to measure inflammatory and oxidative stress markers and potentially enable us to deduce biological causality for our findings. The rationale for using buccal cell-derived DNA in the present 
study was based on the fact that although absolute leukocyte and buccal cell TL values vary, there is a significant intra-individual correlation across the two tissue types (Gadalla et al., 2010). Buccal cell TL measurements also show a significant association with both sex and age, as seen with LTL, providing further evidence of similarities in telomere dynamics between the tissues (Finnicum et al., 2017). Previous work in our laboratory also revealed a significant positive linear relationship between the LTL and buccal cell TL with a large magnitude of association $(r=0.599, \mathrm{p}=<0.0001)$ in a group of young and middle-aged runners $(n=69)$ (supplementary data). In support of the findings by Finnicum et al. and Gadella et al., our supplementary data revealed that buccal cell TL $(0.953 \pm 0.133)$ is significantly longer than LTL $(0.818 \pm 0.121)(\mathrm{p}=<0.0001)$ and both tissue types displayed the expected negative correlation with age $(p=0.006, r=-0.331$ and $p=<0.0001, r=-0.432$, for leukocyte and buccal cell, respectively). Together, these studies demonstrate synchrony in the telomere dynamics of leukocyte and buccal cells, supporting the use of the latter as a viable biomarker of aging.

TL and shortening rate is tissue specific (Aubert and Lansdorp, 2008), with the variability in attrition across tissue types likely the result of divergent proliferative capacities; highly proliferative tissues (e.g. leukocytes and epithelial cells) typically display greater age-related telomere shortening than minimally proliferative tissues (e.g. skeletal muscle) (Kadi and Ponsot, 2010). Many of the studies referenced in the present paper have measured TL across a variety of tissues, which may lead to different associations with TL and exercise performance. However, Daniali et al. revealed that intra-individual age-related telomere attrition is similar across somatic tissues with divergent replicative status (leukocytes, muscle, skin and fat), despite variations in their absolute length (Daniali et al., 2013). This finding suggests that there may be a shared molecular mechanism regulating TL across somatic tissue types. Several other studies have also reported significant correlations in TL 
between tissue types with different proliferative demands (Friedrich et al., 2000; Hiam et al., 2020). To our knowledge, our supplementary data was the first to investigate the relationship between LTL and buccal cell TL in athletes at the time of the present study. As we revealed that TL is strongly correlated across the two tissue types in a group of young and middle-aged runners, we are inclined to believe that buccal cell TL responds to exercise in synchrony with leukocytes (inverted U relationship) and is impacted via the same exercise-induced mechanisms (e.g. inflammation and oxidative stress). More recently, genomic DNA isolated from buccal swabs revealed elderly ultra-trail runners display longer telomeres compared to age-matched sedentary controls (Hernando et al., 2020). Similar studies have also previously shown that ultra-endurance athletes have better preserved telomeres in both skeletal muscle (Østhus et al., 2012) and leukocytes (Denham et al., 2013), suggesting a synchrony in TL across tissue types in response to exercise. Thus, we speculate that the present results would have been replicated in our cohort if TL had been measured in leukocytes (although absolute values would be different). However, it must be stated that there is evidence to suggest that the response of TL to exercise may be unique in skeletal muscle, which is likely caused by their satellite cell content. As exercise promotes muscle damage and stimulates the proliferation of satellite cells (Yin et al., 2013), and telomere attrition occurs with cell division, exercise may cause telomere loss in skeletal muscle tissue of highly active individuals. Chronic endurance running has therefore been reported to shorten skeletal muscle TL due to the increased demand on satellite cells to proliferate and repair damaged tissue (Rae et al., 2010). Long-term exercise also accelerates TL attrition in skeletal muscle in mice, but attenuates age-related decreases in TL in cardiac and liver tissue (Ludlow et al., 2012). Thus, the difference in TL between elite swimmers and controls in the present study may be even more significant when measured in skeletal muscle. Additionally, no study has investigated how exercise specifically impacts replicative stress in the mouth of humans and 
further research is required to determine whether TL responds to exercise in a synchronous or tissue-specific fashion.

Another key finding of the present study is the lack of association between ACE genotype and TL in elite swimmers or controls. It has been previously reported that the presence of the D allele is associated with shortened TL in hypertensive patients with left ventricular hypertrophy (Fyhrquist et al., 2013). Additionally, several previous studies that have reported an excess of the D allele in elite short distance swimming (Costa et al., 2009; Nazarov et al., 2001; Tsianos et al., 2004; Woods et al., 2001). However, our results reveal that TL is not associated with ACE I/D genotype distribution in swimmers or controls. As such, the accelerated telomere attrition displayed by the swimmers in the present study cannot be attributed to a negative effect of the D allele and/or variations in ACE activity. We also observed a lack of association between swimming event distance and ACE I/D genotype. Although this finding is not novel, as the association between ACE I/D genotype and athletic performance is well studied amongst elite swimmers, the duplicability of such an association is contentious. For instance, studies have shown an increased frequency of the I allele with middle- (Nazarov et al., 2001) and longdistance swimming (Tsianos et al., 2004). However, our results reinforce previous reports that show a lack of association between elite long-distance swimming and ACE genotype (Nazarov et al., 2001; Woods et al., 2001) and also between controls and elite swimmers competing in events $>400 \mathrm{~m}$ (Costa et al., 2009). Further research is required to clarify our findings due to the ambiguity of the current literature and based on the limited sample size, the present data should be interpreted with caution.

The novel aspects of our study are that it is the first to specifically investigate the TL of elite swimmers, and to report that elite athletes display shortened telomeres compared to their recreationally active counterparts. Additionally, no study has previously explored the association between ACE genotype and TL in elite athletes. However, the present study is not 
without limitations. For example, we did not control for known certain confounders of TL, such as psychological stress or nutrition. Although 36B4 serves as a commonly used reference gene in conventional qPCR for telomere measurement (Cawthon, 2002; Denham et al., 2013; Hiam et al., 2020), it may amplify pseudogenes on chromosomes 12 and 5. The present study also lacked an additional group of young sedentary controls, which would have permitted us to further explore the 'inverted U' hypothesis and determine whether the elite swimmers had comparable TL to their sedentary peers. As such, further studies investigating the associations between TL, oxidative stress and inflammation in young elite athletes compared with both recreationally active and sedentary subjects are required.

To conclude, the present study reveals that elite female swimmers, who routinely engage in high levels of competition and/or training, possess shorter telomeres than their recreationally active counterparts. Participation in elite level swimming training/competition may therefore be detrimental to telomere maintenance and subsequent biological aging in females, which may be significant in later life as short buccal cell telomeres are associated with age-related disease (Broberg et al., 2005; Thomas et al., 2008). However, as we did not observe an association between ACE I/D genotype distribution and TL in elite swimmers and/or controls, the accelerated telomere attrition detected in elite swimmers does not appear to be influenced by a potential negative effect of the D allele and/or variations in ACE activity.

\section{Acknowledgments}

This study was supported in part by funds from Loughborough University. The funding source was not involved in the study design; in the collection, analysis and interpretation of data; in the writing of the report; and in the decision to submit the article for publication. 
373

374

Aubert, G., Lansdorp, P.M., 2008. Telomeres and aging. Physiol. Rev. 88, 557-579. https://doi.org/10.1152/physrev.00026.2007

Broberg, K., Björk, J., Paulsson, K., Höglund, M., Albin, M., 2005. Constitutional short telomeres are strong genetic susceptibility markers for bladder cancer. Carcinogenesis 26, 1263-1271. https://doi.org/10.1093/carcin/bgi063

Cawthon, R., 2002. Telomere measurement by quantitative PCR. Nucleic Acids Res. 30, 47e - 47. https://doi.org/10.1093/nar/30.10.e47

Cherkas, L., Aviv, A., Valdes, A.M., Hunkin, J.L., Gardner, J.P., Surdulescu, G.L., Kimura, M., Spector, T.D., 2006. The effects of social status on biological aging as measured by white-blood-cell telomere length. Aging Cell 5, 361-365. https://doi.org/10.1111/j.14749726.2006.00222.x

Cherkas, L., Hunkin, J., Kato, B., Richards, J., Gardner, J., Surdulescu, G., Kimura, M., Lu, X., Spector, T., Aviv, A., 2008. The association between physical activity in leisure time and leukocyte telomere length. Arch. Intern. Med. 168, 154-158. https://doi.org/10.1001/archinternmed.2007.39

Collins, M., Renault, V., Grobler, L.A., St. Clair Gibson, A., Lambert, M.I., Derman, E.W., Butler-Browne, G.S., Noakes, T.D., Mouly, V., 2003. Athletes with exercise-associated fatigue have abnormally short muscle DNA telomeres. Med. Sci. Sports Exerc. 35, 1524-1528. https://doi.org/10.1249/01.MSS.0000084522.14168.49

Correia-Melo, C., Hewitt, G., Passos, J.F., 2014. Telomeres, oxidative stress and inflammatory factors: partners in cellular senescence? Longev. Heal. 3, 1-9. https://doi.org/10.1186/2046-2395-3-1 
Costa, A.M., Silva, A.J., Garrido, N.D., Louro, H., de Oliveira, R.J., Breitenfeld, L., 2009. Association between ACE D allele and elite short distance swimming. Eur. J. Appl. Physiol. 106, 785-790. https://doi.org/10.1007/s00421-009-1080-z

Daniali, L., Benetos, A., Susser, E., Kark, J.D., Labat, C., Kimura, M., Desai, K., Granick, M., Aviv, A., 2013. Telomeres shorten at equivalent rates in somatic tissues of adults. Nat. Commun. 4, 1-7. https://doi.org/10.1038/ncomms2602

Denham, J., Nelson, C.P., O’Brien, B.J., Nankervis, S.A., Denniff, M., Harvey, J.T., Marques, F.Z., Codd, V., Zukowska-Szczechowska, E., Samani, N.J., Tomaszewski, M., Charchar, F.J., 2013. Longer Leukocyte Telomeres Are Associated with UltraEndurance Exercise Independent of Cardiovascular Risk Factors. PLoS One 8, e69377. https://doi.org/10.1371/journal.pone.0069377

Finnicum, C.T., Dolan, C. V., Willemsen, G., Weber, Z.M., Petersen, J.L., Beck, J.J., Codd, V., Boomsma, D.I., Davies, G.E., Ehli, E.A., 2017. Relative telomere repeat mass in buccal and leukocyte-derived DNA. PLoS One 12, 1-11. https://doi.org/10.1371/journal.pone.0170765

Friedrich, U., Griese, E.U., Schwab, M., Fritz, P., Thon, K.P., Klotz, U., 2000. Telomere length in different tissues of elderly patients. Mech. Ageing Dev. 119, 89-99. https://doi.org/10.1016/S0047-6374(00)00173-1

Fyhrquist, F., Eriksson, A., Saijonmaa, O., Nordestgaard, B.G., Kontula, K., De Faire, U., Ibsen, H., Kjeldsen, S., Os, I., Dahlöf, B., 2013. Telomere length is associated with ACE I/D polymorphism in hypertensive patients with left ventricular hypertrophy. JRAAS - J. Renin-Angiotensin-Aldosterone Syst. 14, 227-234. https://doi.org/10.1177/1470320312460292

Fyhrquist, F., Saijonmaa, O., 2008. Renin-angiotensin system revisited. J. Intern. Med. 264, 
420

421

422

423

424

425

426

427

428

429

430

431

432

433

434

435

436

437

438

439

440

441

Gadalla, S., Cawthon, R., Giri, N., Alter, B.P., Savage, S.A., 2010. Telomere length in blood, buccal cells, and fibroblasts from patients with inherited bone marrow failure syndromes. Aging (Albany. NY). 2, 867-874. https://doi.org/10.18632/aging.100235

Hernando, B., Gil-Barrachina, M., Tomas-Bort, E., Martinez-Navarro, I., Collado-Boira, E., Hernando, C., 2020. The effect of long-term ultra-endirance exercise and SOD2 genotype on telomere shortening with age.

Hiam, D., Smith, C., Voisin, S., Denham, J., Yan, X., Landen, S., Jacques, M., Alvarezromero, J., Garnham, A., Woessner, M.N., Duque, G., Levinger, I., Eynon, N., 2020. Aerobic capacity and telomere length in human skeletal muscle and leukocytes across the lifespan. Aging (Albany. NY). 12, 1-11.

Huda, N., Tanaka, H., Herbert, B.S., Reed, T., Gilley, D., 2007. Shared environmental factors associated with telomere length maintenance in elderly male twins. Aging Cell 6, 709713. https://doi.org/10.1111/j.1474-9726.2007.00330.x

Kadi, F., Ponsot, E., 2010. The biology of satellite cells and telomeres in human skeletal muscle: Effects of aging and physical activity. Scand. J. Med. Sci. Sport. 20, 39-48. https://doi.org/10.1111/j.1600-0838.2009.00966.x

LaRocca, T., Seals, D.R., Pierce, G.L., 2010. Leukocyte telomere length is preserved with aging in endurance exercise-trained adults and related to maximal aerobic capacity. Mech. Ageing Dev. 131, 165-167. https://doi.org/10.1016/j.mad.2009.12.009

Ludlow, A., Zimmerman, J., Witkowski, S., Hearn, J.W., Hatfield, B.D., Roth, S.M., 2008. Relationship between Physical Activity Level, Telomere Length, and Telomerase Activity. Med. Sci. Sport. Exerc. 40, 1764-1771. 
443

Ludlow, A.T., Witkowski, S., Marshall, M.R., Wang, J., Lima, L.C.J., Guth, L.M., Spangenburg, E.E., Roth, S.M., 2012. Chronic exercise modifies age-related telomere dynamics in a tissue-specific fashion. Journals Gerontol. - Ser. A Biol. Sci. Med. Sci. 67 A, 911-926. https://doi.org/10.1093/gerona/gls002

Margonis, K., Fatouros, I.G., Jamurtas, A.Z., Nikolaidis, M.G., Douroudos, I., Chatzinikolaou, A., Mitrakou, A., Mastorakos, G., Papassotiriou, I., Taxildaris, K., Kouretas, D., 2007. Oxidative stress biomarkers responses to physical overtraining: Implications for diagnosis. Free Radic. Biol. Med. 43, 901-910. https://doi.org/10.1016/j.freeradbiomed.2007.05.022

Mofrad, S., Ebrahim, K., 2018. The effect of high intensity interval training on telomere length and telomerase activity in non-athlete young men. J. Basic Res. Med. Sci. 5, 1-7.

Muniesa, C., Verde, Z., Diaz-Ureña, G., Santiago, C., Gutiérrez, F., Díaz, E., GómezGallego, F., Pareja-Galeano, H., Soares-Miranda, L., Lucia, A., 2017. Telomere length in elite athletes. Int. J. Sports Physiol. Perform. 12, 994-996. https://doi.org/10.1123/ijspp.2016-0471

Nazarov, I., Woods, D.R., Montgomery, H.E., Shneider, O. V., Kazakov, V.I., Tomilin, N. V., Rogozkin, V.A., 2001. The angiotensin converting enzyme I/D polymorphism in Russian athletes. Eur. J. Hum. Genet. 9, 797-801. https://doi.org/10.1038/sj.ejhg.5200711

Nickels, M., Mastana, S., Hunter, D., Denniff, M., Codd, V., Akam, E., 2020. The effect of a 12-week resistance training intervention on leukocyte telomere length. Heliyon 6, e04151. https://doi.org/10.1016/j.heliyon.2020.e04151 
Olovnikov, A., 1973. A theory of marginotomy. The incomplete copying of template margin in enzymic synthesis of polynucleotides and biological significance of the phenomenon. J. Theor. Biol. 41, 181-190. https://doi.org/10.1016/0022-5193(73)90198-7

Østhus, I.B., Sgura, A., Berardinelli, F., Alsnes, I.V., Brønstad, E., Rehn, T., Støbakk, P.K., Hatle, H., Wisløff, U., Nauman, J., 2012. Telomere Length and Long-Term Endurance Exercise: Does Exercise Training Affect Biological Age? A Pilot Study. PLoS One 7. https://doi.org/10.1371/journal.pone.0052769

Rae, D., Vignaud, A., Butler-Browne, G.S., Thornell, L.E., Sinclair-Smith, C., Derman, E.W., Lambert, M.I., Collins, M., 2010. Skeletal muscle telomere length in healthy, experienced, endurance runners. Eur. J. Appl. Physiol. 109, 323-330. https://doi.org/10.1007/s00421-010-1353-6

Rigat, B., Hubert, C., Alhenc-Gelas, F., Cambien, F., Corvol, P., Soubrier, F., 1990. An insertion/deletion polymorphism in the angiotensin I-converting enzyme gene accounting for half the variance of serum enzyme levels. J. Clin. Invest. 86, 1343-1346. https://doi.org/10.1172/JCI114844

Rizvi, S., Raza, S.T., Mahdi, F., 2015. Telomere Length Variations in Aging and AgeRelated Diseases. Curr. Aging Sci. 7, 161-167. https://doi.org/10.2174/1874609808666150122153151

Saßenroth, D., Meyer, A., Salewsky, B., Kroh, M., Norman, K., Steinhagen-Thiessen, E., Demuth, I., 2015. Sports and exercise at different ages and leukocyte telomere length in later life - Data from the Berlin Aging Study II (BASE-II). PLoS One 10, 1-13. https://doi.org/10.1371/journal.pone.0142131

Savela, S., Saijonmaa, O., Strandberg, T.E., Koistinen, P., Strandberg, A.Y., Tilvis, R.S., Pitkälä, K.H., Miettinen, T.A., Fyhrquist, F., 2012. Physical activity in midlife and 
telomere length measured in old age. Exp. Gerontol. 48, 81-84. https://doi.org/10.1016/j.exger.2012.02.003

Starkweather, A., 2014. An Integrative Review of Factors Associated with Telomere Length and Implications for Biobehavioral Research. Nurs. Res. 63, 36-50. https://doi.org/10.1038/jid.2014.371

Thomas, P., O’ Callaghan, N.J., Fenech, M., 2008. Telomere length in white blood cells, buccal cells and brain tissue and its variation with ageing and Alzheimer's disease. Mech. Ageing Dev. 129, 183-190. https://doi.org/10.1016/j.mad.2007.12.004

Tsianos, G., Sanders, J., Dhamrait, S., Humphries, S., Grant, S., Montgomery, H., 2004. The ACE gene insertion/deletion polymorphism and elite endurance swimming. Eur. J. Appl. Physiol. 92, 360-362. https://doi.org/10.1007/s00421-004-1120-7

Werner, C., Fürster, T., Widmann, T., Pöss, J., Roggia, C., Hanhoun, M., Scharhag, J., Büchner, N., Meyer, T., Kindermann, W., Haendeler, J., Böhm, M., Laufs, U., 2009. Physical exercise prevents cellular senescence in circulating leukocytes and in the vessel wall. Circulation 120, 2438-2447. https://doi.org/10.1161/CIRCULATIONAHA.109.861005

Woods, D., Hickman, M., Jamshidi, Y., Brull, D., Vassiliou, V., Jones, A., Humphries, S., Montgomery, H., 2001. Elite swimmers and the D allele of the ACE I/D polymorphism. Hum. Genet. 108, 230-232. https://doi.org/10.1007/s004390100466

Yin, H., Price, F., Rudnicki, M.A., 2013. Satellite cells and the muscle stem cell niche. Physiol. Rev. 93, 23-67. https://doi.org/10.1152/physrev.00043.2011

Zhu, H., Wang, X., Gutin, B., Davis, C.L., Keeton, D., Thomas, J., Stallmann-Jorgensen, I., Mooken, G., Bundy, V., Snieder, H., Van Der Harst, P., Dong, Y., 2011. Leukocyte 

telomere length in healthy caucasian and african-american adolescents: Relationships with race, sex, adiposity, adipokines, and physical activity. J. Pediatr. 158, 215-220. https://doi.org/10.1016/j.jpeds.2010.08.007 